\author{
Mathieu van der Jagt \\ Iain Haitsma
}

\section{An injured brain needs cooling down: no}

Received: 3 March 2015

Accepted: 3 April 2015

Published online: 8 May 2015

(C) Springer-Verlag Berlin Heidelberg and ESICM 2015

For a contrasting viewpoint, please go to

doi:10.1007/s00134-015-3798-x.

M. van der Jagt (凶)

Department of Intensive Care, Erasmus Medical Center Rotterdam, Room H-611, 's-Gravendijkwal 230, 3015 CE Rotterdam,

The Netherlands

e-mail: m.vanderjagt@erasmusmc.nl

Tel.: +31 643791305

\section{Haitsma}

Department of Neurosurgery, Erasmus Medical Center Rotterdam, 's-Gravendijkwal 230, 3015 CE Rotterdam,

The Netherlands

e-mail: i.haitsma@erasmusmc.nl

There is no conclusive evidence that therapeutic hypothermia for traumatic brain injury (TBI), stroke or central nervous system (CNS) infections improves outcomes [1]. Robust evidence is even unavailable for fever control in the acute phase after these types of brain injury (excluding comatose patients after cardiac arrest for whom fever control does result in improved outcomes), and authors of practice guidelines have therefore been reluctant to recommend fever control [2-4]. The only way to prove that fever is causally linked to poor outcomes is to perform prospective randomized controlled studies that show improved outcomes with fever control versus no fever control, but such studies have not been done in TBI, stroke or CNS infections.

A large observational multinational cohort study $(n=110,638)$ on patients with acute brain injuries recently published in Intensive Care Medicine by Saxena et al. [5] adds importantly to the literature on which temperatures early after the brain insult may be regarded as "normal". The results indicate that both hypothermia (below $37^{\circ} \mathrm{C}$ ) and hyperthermia (above $39{ }^{\circ} \mathrm{C}$ ) on admission are associated with increased mortality in stroke and TBI after rigorous adjustment for potential confounders, whereas hyperthermia was not associated with increased mortality in patients with CNS infections. Although the relationship of hyperthermia with increased mortality in stroke and TBI does not seem surprising given the abundance of observational studies reporting this, the association of hypothermia with increased mortality was more complex to interpret. The authors acknowledged that the association between early hypothermia and increased mortality was not necessarily causal. But the signal of potential harm is conspicuous and at the least another indication that therapeutic hypothermia is not an established treatment for acute brain injury. Maybe the most interesting result is the finding that temperatures between 37.0 and $39.0{ }^{\circ} \mathrm{C}$ were not associated with increased mortality. However, this finding should be regarded as "hypothesis generating" rather than indicating that temperatures up to $39^{\circ} \mathrm{C}$ are harmless. Furthermore, this work supports the concept that cooling down the brain regardless the aetiology of brain injury may not be the right approach. Finally, an important point to consider in interpreting this study is that hypothermia was accidental or iatrogenic rather than therapeutic.

To advance our knowledge on therapeutic hypothermia and temperature management in brain injuries several issues need to be addressed in future studies.

First, it should be clearly defined where the brain comes from in terms of temperatures ("cooling down" from what?) and where the brain is headed. Future studies should be very clear on what they aim to compare: for instance hypothermia (e.g. below 36 or $37^{\circ} \mathrm{C}$ ) versus strict normothermia (avoiding any fever above 38.0 or 
$39.0^{\circ} \mathrm{C}$ ), or strict normothermia versus a strategy that aims to control fever once it occurs (treatment of fever, see also Fig. 1). The targeted temperature management (TTM) trial [6] showed that aiming for a body temperature of $36{ }^{\circ} \mathrm{C}$ resulted in an upper limit of the $95 \%$ confidence interval of recorded temperatures of between 37.0 and $37.5^{\circ} \mathrm{C}$, meaning that this strategy resulted in strict avoidance of fever, which was not inferior to mild hypothermia $\left(33{ }^{\circ} \mathrm{C}\right)$ in comatose patients after cardiac arrest. The results have pointed out that previous hypothermia trials may have actually compared hypothermia versus a strategy allowing for the occurrence of fever, which is not the same as strict normothermia $[7,8]$. This insight was one of the reasons to perform the TTM trial: was the beneficial effect of mild hypothermia caused by the avoidance of fever rather than the hypothermia itself? As already referred to before, the evidence from the TTM trial and the previous seminal trials by Bernard et al. [8] and the HACA investigators [9] combined may constitute the strongest evidence to date indicating that fever in the first day(s) after ischaemic-anoxic acute brain injury is harmful, thus indicating that strictly avoiding fever in the first days after cardiac arrest and coma is a wise thing to do.
Second, it should be clarified how the "cooling down" should be established, maintained and terminated. The NABISH-II trial [10] did not lend support to the idea that earlier, faster cooling after TBI improved clinical outcomes, but potential adverse effects of rewarming the patients too fast, independently of intracranial pressures, may have negated possible beneficial effects of earlier cooling, indicating that both "cooling down" and rewarming matter. Results are eagerly awaited from the EUROTHERM3235 trial, funded by the European Society of Intensive Care Medicine and aimed at assessing the effects of targeted hypothermia after TBI with increased intracranial pressure (ICP), which has in its design elegantly aimed at avoiding circumstances that were associated with adverse outcomes in previous studies, such as hypothermia duration less than $48 \mathrm{~h}$, and the POLARRCT sponsored by the Australian and New Zealand Intensive Care Research Centre [11, 12]. Endovascular cooling is widely applied after cardiac arrest and coma, but may be more challenging in TBI since it should generally be applied for several days in patients who may have haemorrhagic lesions in the brain and a relative contraindication for anticoagulation, which has been shown to result in a high incidence of venous catheter-

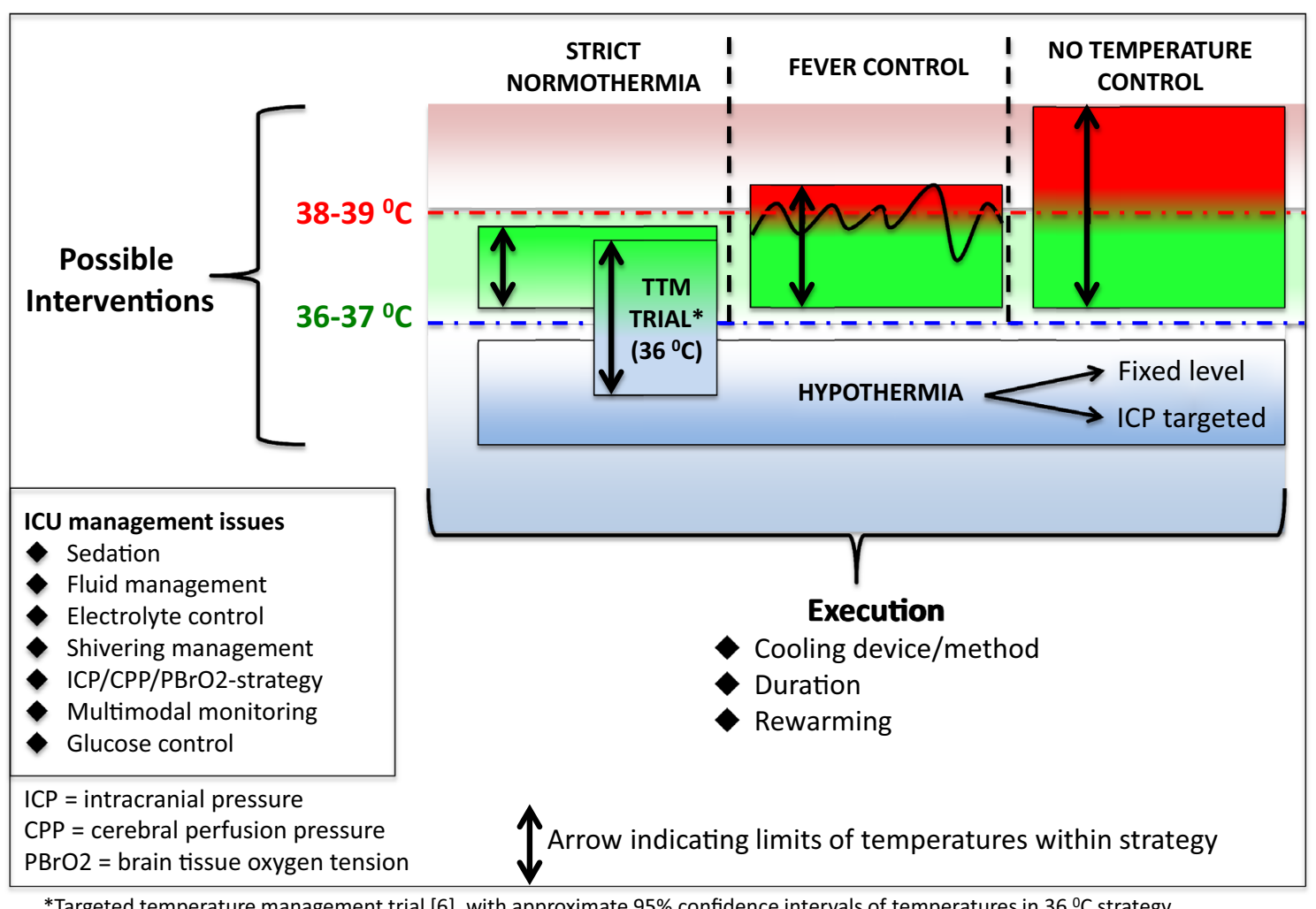

Fig. 1 Showing several interventions on temperature management to be considered for future studies, items to evaluate in the execution of the temperature management, and important ICUrelated issues to be included in a study protocol. An important point is the difference between "strict normothermia" which may be defined as avoiding any fever, whereas "fever control" is aimed at mitigating fever once it has occurred 
related thrombosis [13]. On the other hand, surface cooling avoids these problems, but seems inferior to intravascular cooling in maintaining a stable target temperature [14]. Intranasal cooling for the brain is a relatively new technique, which may further enrich the armamentarium [15]. Further, optimal duration of therapeutic hypothermia, rate of rewarming, method of temperature measurements (core versus other) and the role of neuromonitoring in temperature management require further evaluation.

Third, the associated ICU treatments should be taken into account since these may impact on the outcomes independently from temperature management. Examples are sedation, ICP- versus more cerebral perfusion pressure (CPP)-oriented strategies and experience in temperature management.

In summary, before we can conclude that "an injured brain needs cooling down", many issues require further clarification including the optimal temperature level, methods and duration of temperature control and the (re)definition of what constitutes a normal temperature to begin with.

Conflicts of interest On behalf of all authors, the corresponding author states that there is no conflict of interest.

\section{References}

1. Bohman LE, Levine JM (2014) Fever and therapeutic normothermia in severe brain injury: an update. Curr Opin Crit Care 20:182-188

2. Childs C, Wieloch T, Lecky F, Machin G, Harris B, Stocchetti N (2010) Report of a consensus meeting on human brain temperature after severe traumatic brain injury: its measurement and management during pyrexia. Front Neurol 1:146

3. Le Roux P, Menon DK, Citerio G, Vespa P, Bader MK, Brophy G, Diringer MN, Stocchetti N, Videtta W, Armonda R, Badjatia N, Bösel J, Chesnut R, Chou S, Claassen J, Czosnyka M, De Georgia M, Figaji A, Fugate J, Helbok R, Horowitz D, Hutchinson P, Kumar M, McNett M, Naidech A, Oddo M, Olson D, O'Phelan K, Provencio JJ, Puppo C, Riker R, Roberson C, Schmidt M, Taccone F (2014) The international multidisciplinary consensus conference on multimodality monitoring in neurocritical care: a list of recommendations and additional conclusions. A statement for healthcare professionals from the Neurocritical Care Society and the European Society of Intensive Care. Neurocrit Care 21(2):282-296

4. Scaravilli V, Tinchero G, Citerio G (2011) Fever management in SAH. Neurocrit Care 15:287-294

5. Saxena M, Young P, Pilcher D, Bailey M, Harrison D, Bellomo R, Finfer S, Beasley R, Hyam J, Menon D, Rowan K, Myburgh J (2015) Early temperature and mortality in critically ill patients with acute neurological diseases: trauma and stroke differ from infection. Intensive Care Med. doi: 10.1007/s00134-015-3676-6
6. Nielsen N, Wetterslev J, Cronberg T, Erlinge D, Gasche Y, Hassager C, Horn J, Hovdenes J, Kjaergaard J, Kuiper M, Pellis T, Stammet P, Wanscher M, Wise MP, Aneman A, Al-Subaie N, Boesgaard S, Bro-Jeppesen J, Brunetti I, Bugge JF, Hingston CD, Juffermans NP, Koopmans M, Køber L, Langørgen J, Lilja G, Møller JE, Rundgren M, Rylander C, Smid O, Werer C, Winkel $\mathrm{P}$, Friberg H, Trial Investigators TTM (2013) Targeted temperature management at 33 versus $36{ }^{\circ} \mathrm{C}$ after cardiac arrest. $\mathrm{N}$ Engl $\mathrm{J}$ Med 369:2197-2206

7. Clifton GL, Miller ER, Choi SC, Levin HS, McCauley S, Smith KR Jr, Muizelaar JP, Wagner FC Jr, Marion DW, Luerssen TG, Chesnut RM, Schwartz M (2001) Lack of effect of induction of hypothermia after acute brain injury. N Engl J Med 344:556-563

8. Bernard SA, Gray TW, Buist MD, Jones BM, Silvester W, Gutteridge G, Smith K (2002) Treatment of comatose survivors of out-of-hospital cardiac arrest with induced hypothermia. N Engl J Med 346:557-563

9. Hypothermia after cardiac arrest study group (2002) Mild therapeutic hypothermia to improve the neurologic outcome after cardiac arrest. N Engl J Med 346:549-556

10. Clifton GL, Valadka A, Zygun D, Coffey CS, Drever P, Fourwinds S, Janis LS, Wilde E, Taylor P, Harshman K, Conley A, Puccio A, Levin HS, McCauley SR, Bucholz RD, Smith KR, Schmidt JH, Scott JN, Yonas H, Okonkwo DO (2011) Very early hypothermia induction in patients with severe brain injury (the National Acute Brain Injury Study: Hypothermia II): a randomised trial. Lancet Neurol 10:131-139
11. Andrews PJ, Sinclair HL, Battison CG, Polderman KH, Citerio G, Mascia L, Harris BA, Murray GD, Stocchetti N, Menon DK, Shakur H, De Backer D, Eurotherm3235Trial collaborators (2011) European Society of Intensive Care Medicine study of therapeutic hypothermia $\left(32-35^{\circ} \mathrm{C}\right)$ for intracranial pressure reduction after traumatic brain injury (the Eurotherm3235Trial). Trials $12: 8$

12. Australian and New Zealand Intensive Care Research Centre (2015) POLARRCT. https://clinicaltrials.gov/ ct2/show/NCT00987688

13. Maze R, Le May MR, Froeschl M, Hazra SK, Wells PS, Osborne C, Labinaz M, Hibbert B, So DY, CArdiovascular Percutaneous Intervention TriAL (CAPITAL) investigators (2014) Endovascular cooling catheter related thrombosis in patients undergoing therapeutic hypothermia for out of hospital cardiac arrest. Resuscitation 85:1354-1358

14. Hoedemaekers CW, Ezzahti M, Gerritsen A, Van der Hoeven JG (2007) Comparison of cooling methods to induce and maintain normo- and hypothermia in intensive care unit patients: a prospective intervention study. Crit Care 11:R91

15. Covaciu L, Weis J, Bengtsson C, Allers $\mathrm{M}$, Lunderquist A, Ahlstrom $\mathrm{H}$, Rubertsson S (2011) Brain temperature in volunteers subjected to intranasal cooling. Intensive Care Med 37:1277-1284 